\title{
A concepção produtivista da educação: A trajetória de estudantes universitários
}

\author{
The productivist conception of education: The trajectory of university students \\ La concepción productivista de la educación: La trayectoria de estudiantes universitarios
}

Recebido: 01/04/2021 | Revisado: 10/04/2021 | Aceito: 13/04/2021 | Publicado: 26/04/2021

Paula Pamplona Beltrão da Silva
ORCID: https://orcid.org/0000-0002-9123-2610
Universidade Federal do Pará, Brasil
E-mail: paula.beltrao@ifch.ufpa.br
Andréa Bittencourt Pires Chaves
ORCID: https://orcid.org/0000-0003-0247-9265
Universidade Federal do Pará, Brasil
E-mail: andreachaves@ufpa.br

\begin{abstract}
Resumo
A Constituição Federal de 1988 prevê que o primado do trabalho é a base da ordem social e que a educação é um direito de todos e dever do Estado e da família. Importa neste artigo descrever a forma pela qual o Estado brasileiro falha quando não observa que garantir o acesso a educação pública federal de nível superior também é assegurar a permanência do estudante no processo de aprendizado até sua conclusão. Assim, foi aplicada pesquisa exploratória, com metodologia de abordagem hipotético-dedutiva e método de procedimento bibliográfico, concomitante com estudo de campo. Os resultados mostram que há relação entre as políticas de educação no Brasil e o fenômeno da precarização do trabalho e da evasão universitária. Conclui-se que a concepção produtivista da educação no Brasil reforça os problemas que envolvem a permanência dos estudantes na educação pública federal de nível superior. Em pesquisa de campo, na qual foram entrevistados 4 (quatro) estudantes da Universidade Federal do Pará - UFPA, os dados são uníssonos no sentido de que estudantes que possuem renda familiar baixa, pois no seio de suas famílias a renda advém do trabalho precarizado, encaram com incerteza sua permanência no curso universitário devido aos custos de deslocamento, alimentação e material didático, situação que os compele a também praticar formas de trabalho precárias, como a venda de produtos, para que possam se manter no processo de aprendizado.
\end{abstract}

Palavras-chave: Educação; Ensino; Precarização; Políticas; Evasão universitária.

\begin{abstract}
The Federal Constitution of 1988 provides that the primacy of work is the basis of the social order and that education is a right for all and a duty of the State and the family. It is important in this article to describe the way in which the Brazilian State fails when it does not observe that guaranteeing access to federal public higher education is also ensuring the student's permanence in the learning process until its conclusion. Thus, exploratory research was applied, with a hypothetical-deductive approach methodology and bibliographic procedure method, concomitant with field study. The results show that there is a relationship between education policies in Brazil and the phenomenon of job insecurity and university evasion. It is concluded that the productivist conception of education in Brazil reinforces the problems that involve the students' permanence in the federal public education of superior level. In field research, which 4 (four) students from the Federal University of Pará - UFPA were interviewed, the data are unanimous in the sense that students who have low family income, because within their families, the income comes from precarious work, they face with uncertainty their permanence in the university course due to the costs of commuting, food and didactic material, a situation that compels them to also practice precarious forms of work, such as the sale of products, so that they can remain in the learning process.
\end{abstract}

Keywords: Education; Teaching; Precarization; Policies; University dropout.

\section{Resumen}

La Constitución Federal de 1988 establece que la primacía del trabajo es la base del orden social y que la educación es un derecho de todos y un deber del Estado y de la familia. Es importante en este artículo describir la forma en que falla el Estado brasileño cuando no observa que garantizar el acceso a la educación pública federal en un nivel superior es también asegurar la permanencia del estudiante en el proceso de aprendizaje hasta su conclusión. Así, se aplicó una investigación exploratoria, con una metodología de enfoque hipotético-deductivo y un método de procedimiento bibliográfico, concomitante con el estudio de campo. Los resultados muestran que existe una relación entre las políticas educativas en Brasil y el fenómeno de la precariedad laboral y la evasión universitaria. Se concluye que la concepción productivista de la educación en Brasil refuerza los problemas que involucran la permanencia de los estudiantes en la educación pública federal de nivel superior, pues en la investigación de campo, en la que se 
entrevistaron 4 (cuatro) estudiantes de la Universidad Federal de Pará - UFPA, los datos son unánimes en el sentido de que los estudiantes que tienen bajos ingresos familiares, porque dentro de sus familias los ingresos provienen del trabajo precario, enfrentan su permanencia en la carrera universitaria con incertidumbre debido a los costos de viaje, alimentación y material didáctico, situación que les obliga a practicar formas de trabajo precarias, como vender productos, para que puedan permanecer en el proceso de aprendizaje.

Palabras clave: Educación; Enseñanza; Precariedad; Políticas; Abandono universitario.

\section{Introdução}

O que a sociedade espera da Universidade pública quanto instituição de ensino superior? Está pergunta é uma adaptação do questionamento levantado por José Saramago (2013) no livro Democracia e Universidade no qual o renomado escritor português discorre sobre a importância da força institucional da Universidade no desenvolvimento de valores e garantias importantes para a sociedade, tais como: oportunidade, igualdade e justiça.

O Brasil, neste século XXI, está sob o julgo da "desterritorialização das políticas educativas" (Giovanni \& Nogueira, 2018, p. 313), onde é questionado tanto o futuro dos sistemas educativos como o papel do Estado-Nação na condição de mediador entre a comunidade pedagógica e as mudanças tecnológicas, o multiculturalismo advindo da globalização. Ao Estado foi delegado o controle da educação para a formação do cidadão (Azevedo, 2017) e neste ponto pode estar o problema de politizar a educação.

O questionamento instiga a pensar a relação entre a evasão universitária com a concepção produtivista da educação (Saviani, 2006) e o fenômeno da precarização do trabalho. Assim, este artigo tem por objetivo identificar como o papel político desempenhado pelo Estado afeta a ordem social da educação, citando as principais normas textuais que regem a matéria; exemplificar a maneira pela qual as relações educacionais são condicionadas pelo posicionamento político; e delimitar as consequências precarizantes dessa relação para o estudante de nível superior.

\section{Metodologia}

O delineamento proposto no projeto é de base exploratória, pois tem como objetivo "proporcionar maior familiaridade com o problema, com vistas a torná-lo mais explícito ou a construir hipóteses" (Gil, 2002, p.41).

Para alcançar essa finalidade a pesquisa envolve metodologia de abordagem hipotético-dedutiva, partindo da teoria ao particular e retornando à teoria, no sentido de reanalisar sua aplicação no contexto diferente daquele no qual a teoria foi produzida originalmente.

Aplicado o método de procedimento monográfico e estudo de campo, concomitantemente, as etapas são divididas em: 1) revisão bibliográfica, a partir da qual foi identificado material teórico adequado ao tema proposto; e 2) Pesquisa de campo, realizada em dezembro de 2019 por meio de entrevista semiestruturada com 4 (quatro) alunos de Graduação da Universidade Federal do Pará, 3 (três) do sexo feminino e 1 (um) do sexo masculino, entre 18 e 21 anos, que praticam a atividade informal de vendas de produtos no ambiente universitário do campus Guamá, em Belém-Pa. O número de entrevistas realizadas correspondeu ao objetivo da pesquisa e a capacidade dos entrevistados em revelar informações de monta para a compreensão do tema em questão.

A entrevista semiestruturada foi realizada individualmente, precedida da assinatura de Termo de Consentimento Livre e Esclarecido - TCLE, e teve por base ética um conjunto de perguntas respondidas livremente pelos entrevistados.

Assim foram compilados os dados referentes às respostas acerca das seguintes perguntas fechadas: (I) Você vende produtos no campus universitário?; (II) Seu acesso à universidade foi fomentado por políticas públicas de cota?; (III) Sua permanência no ambiente universitário está sendo fomentado por políticas públicas, de iniciação científica ou estágio 
universitário?; (IV) Na sua família alguém possui renda fixa?; (V) Você espera atuar como profissional de psicologia após a sua formação?; (VI) Você utiliza o Restaurante Universitário para realizar refeições?.

Houveram 3 (três) perguntas abertas: (a) Porque você vende produtos no campus universitário? (b) Qual a importância do Restaurante universitário para você?; (c) Qual sua perspectiva para o futuro?.

Todas as respostas foram transcritas nos formulários de entrevista, e, após análise, os dados foram condensados neste artigo, que está dividido em introdução, metodologia, resultados e discussões, com 4 (quatro) subtópicos, e as considerações finais.

\section{Resultados e Discussão}

\subsection{Educação: entre direito e política}

Na Constituição Federal de 1988 alguns dos princípios fundamentais da República Federativa do Brasil são os valores sociais do trabalho e da livre iniciativa, o trabalho e a educação também são bases da ordem social. A Lei n. ${ }^{\circ}$ 9.394/96 (Brasil, 1996), que estabelece as diretrizes e bases da educação nacional, perpetua esses princípios, tendo por norte a cidadania e a qualificação para o trabalho.

A Lei de Diretrizes e Bases da Educação Nacional - LDB, como a conhecemos na Lei n.o 9.394/96 (Brasil, 1996), passou por reformulações no decurso do tempo, com destaque para a Lei n. ${ }^{\circ} 5.692 / 71$ (Brasil, 1971) que criada no curso da ditadura militar no Brasil, teve como objetivo principal o fomento ao ensino profissional, que visava capacitar as pessoas ao exercício do trabalho de produção, em detrimento do desenvolvimento de um plano direcionado a formação intelectual que seria contestadora do regime (Sousa, 2020).

Portanto, ao tratar o acesso à educação, este vocábulo será aqui empregado como: o ensino e instrução, nos parâmetros previsto na LDB de 1996, na condição de garantia do Estado (representativo) para a população (representada), que ao usufruir desse direito alcança o protagonismo da cidadania. Para Pinsky (2018) a cidadania é uma noção advinda das transformações do capitalismo e salvaguarda a importância dos direitos sociais como a educação e o trabalho, que quando plenamente exercido são considerados o auge da democracia - garantia ao acesso à direitos e oportunidades.

Neste sentido é oportuna a posição de Malan $(2018$, p.50) de que "uma democracia moderna deveria dispensar salvadores da pátria, messiânicos, voluntaristas e autoritários. Uma democracia moderna precisa, tanto na sociedade quanto no governo, de serenidade para enfrentar os inúmeros desafios de forma eficaz". A sociedade tem tanta responsabilidade no exercício da cidadania quanto o Estado no exercício de sua representatividade.

Santos (2002, p.34) pontua que a relação política do Brasil com a educação segue um curso em busca de adaptar o ensino a algo instrumental que sirva ao processo globalizado e para isso são manejados "pactos sociais através de contradições e compromissos, pressões e acordos, avanços e retrocessos. Daí resultará a construção de um compêndio legal que irá presidir às regras de convivência da sociedade civil".

A educação não é política, mas sim um direito que deveria ser efetivado pela política. No entanto, há evidências de que a educação está sendo absorvida pela política pois as construções legislativas que deveriam proteger esse direito humano fundamental, de segunda geração, estão sendo manejada conforme interesses políticos atendendo questões relacionadas à capitalização da educação como mercadoria.

Seguindo o raciocínio de que a realidade objetiva é condicionada pela educação, que por sua vez pode ser manejada pelo Código e seus intérpretes (Durkheim, 2007), quando o governo brasileiro aplica políticas neoliberais tratando as ações educacionais a partir de questões de ordem fiscal, com base na arrecadação tributária e no contingenciamento advindo do Ministério da Economia, atrela a educação às questões de mercado. 
Em um processo antropofágico o capital se alimenta das resistências e incorpora suas lutas como se fossem "ganhos de direito", assim a educação passa a ser manejada como mecanismo redutor da desigualdade, sendo que, em verdade a desigualdade é um problema inerente ao sistema capitalista (Claves \& Almeida, 2020).

\subsection{A base política da concepção produtivista da educação}

A concepção produtivista da educação no Brasil é pautada pelo fomento da mais-valia social. Nesse sentido, a problemática está em torno da adoção de um modelo de crescimento orientado para fora, no qual as políticas implantadas buscam o incentivo mais a instalação e operação de capital estrangeiro, que normalmente se apropriam "da mais-valia social local, que elas mandam para fora ou utilizam para incrementar seus ativos e aumentar, assim, suas possibilidades de ampliar a própria mais-valia" (Santos, 2005, p. 46), em detrimento do desenvolvimento do setor produtivo.

Oposto do que ocorre na China, que adota políticas de incentivo a instalação de empresas de produção e desenvolvimento de tecnologias locais, para alcance global, fomentadas pelo aproveitamento de mão de obra nacional, qualificada desde as bases educacionais para esta finalidade.

Como expõe Geromel (2019, p. 54, conforme o original), no livro O poder da China, "nessa nova economia digital, a matéria-prima primordial é o pessoal bem qualificado. O governo chinês lançou o famoso 'Plano de Mil Talentos' em 2008 e já recrutou mais de 7 mil pesquisadores e cientistas estrangeiros e chineses que moram fora para os incentiva a viver na China".

A sociedade brasileira, por representação política, adota a concepção produtivista da educação, e de maneira contraditória adota uma política social e econômica que desestimula a formação de um contingente qualitativo, e apinha um elenco quantitativo de trabalhadores, que se redistribui e reorganiza para atender a divisão do trabalho que está estagnada em termos de criação de valor local, sempre dependente de desenvolvimento econômico externo.

Segundo a jornalista Raquel Faria (2019) os investimentos estão sendo utilizados para aquisições de bens no Brasil, que adota uma política de rateio e venda de seus ativos, assim, o Capital compra no Brasil, mas não expande seus negócios. Por isso as políticas adotadas empobrecem o Estado desvalorizando recursos nacionais em oposição a criação de atividades produtivas para o trabalhador brasileiro.

Como prediz o liberalismo de Milton Friedman (2017, p.31), o Estado, consubstanciado na sociedade, deve ter responsabilidade, "O papel do governo é fazer algo que o mercado em si não é capaz de realizar, ou seja, determinar, arbitrar e aplicar as regras do jogo". Pois, como prediz a máxima neoliberalista, os países que vendem suas riquezas, seus ativos, são aqueles que estão manejando uma gestão compatível com seu desenvolvimento.

Neste sentido é plausível a ponderação de Malan (2018, p.37) quanto a necessidade de "eficiência operacional do Estado (nos três níveis de governo) na utilização de recursos públicos e na mobilização da sociedade civil para alcançar, ao longo do tempo objetivos sociais..." para alavancar o desenvolvimento econômico e social.

\subsection{A precarização do estudante}

A precarização do estudante não é somente uma analogia à precarização do trabalho, pois está inserida nesta estrutura. O precarizado se baseia na instabilidade dentro das relações, que na seara da instrução profissional se manifesta pela falta de previsibilidade para questões básicas como a permanência do discente com baixa renda (menor poder aquisitivo) na graduação, reforçada pelo descompasso entre a demanda e as reais oportunidades de emprego ou estágio.

Para descrever os efeitos práticos do fenômeno da precarização em suas vertentes trabalho e educação foi realizada entrevista semiestruturada com 4 (quatro) alunos de Graduação da Universidade Federal do Pará, 3 (três) do sexo feminino e 1 (um) do sexo masculino, entre 18 e 21 anos, que praticam a atividade informal de vendas de produtos no ambiente universitário do campus Guamá, em Belém-Pa. 
Para assegurar o anonimato dos participantes, em consonância com a ética na pesquisa, cada um dos entrevistados recebeu uma denominação genérica neste artigo, P1 (participante 1), P2 (participante 2), P3 (participante 3) e P4 (participante 4). Assim, obteve-se os seguintes indicadores.

Tabela 1 - Compilação dos resultados das entrevistas com os universitários - perguntas fechadas.

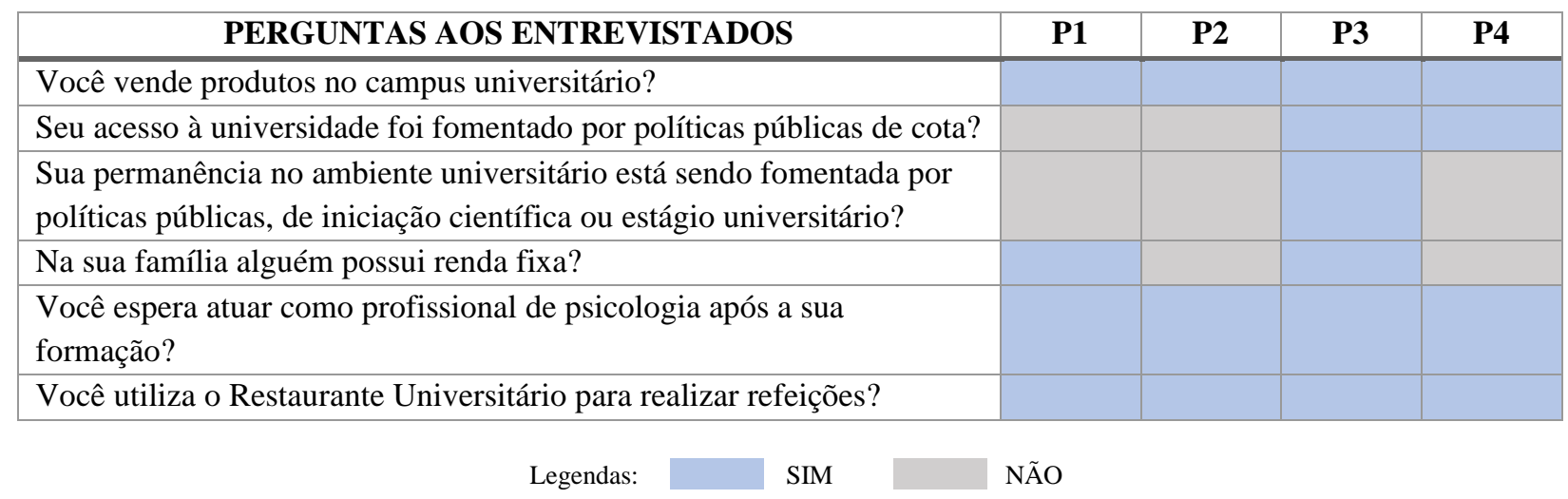

Fonte: Autores, a partir de entrevista semiestruturada realizada em dezembro de 2019 com estudantes da UFPA.

Foram feitas 6 (seis) perguntas fechadas aos 4 (quatro) participantes que responderam afirmativamente à prática de venda informal, desses, $50 \%$ (cinquenta por cento) ingressaram por meio de alguma política de ação afirmativa, 75\% (setenta e cinco por cento) dos participantes não recebe qualquer auxílio permanência vinculado a alguma política pública. 50\% (cinquenta por cento) dos participantes tem algum familiar com renda fixa. Todos os participantes querem atuar profissionalmente no campo de sua graduação, que neste caso é a psicologia, e todos responderam que utilizam o Restaurante Universitário para realizar refeições.

Outras 3 (três) perguntas abertas também foram realizadas: (a) Porque você vende produtos no campus universitário? (b) Qual a importância do Restaurante universitário para você?; (c) Qual sua perspectiva para o futuro?. Todos os participantes aceitaram responder e houve um parâmetro de resposta consensual para todos os questionamentos, de que a venda dos produtos é uma maneira de auxiliar tanto na vida doméstica, quanto na vida acadêmica, para custear o transporte público, materiais de papelaria, materiais do ensino da graduação e, inclusive, a alimentação no restaurante universitário que foi citado por todos como um serviço de extrema importância.

Quanto a pergunta (c) Qual sua perspectiva para o futuro? O P1 respondeu: "Não sei, se não der certo com os produtos, diversificar para novos, bicos, serviços rápidos. Espero emprego rápido"; P2 se manifestou dizendo: "Gostaria de conseguir uma bolsa de pesquisa. Mas pretendo montar uma loja para vender eletrônicos. Atuar em psicologia também”; P3 afirma: "Eu pretendo continuar, possuo estágio, pretendo seguir carreira acadêmica, especializações e tudo o mais"; a perspectiva de P4 é completar os estudos e sempre que possível complementar renda.

Ao analisar as condições do trabalho informal para a permanência do discente na Universidade Pública é certo a dicotomia contida no processo de acesso ao ensino superior e a questão do incentivo a permanência destes estudantes no quadro universitário até a completude de sua formação.

Por analogia, é pertinente uma inferência, com base nas respostas da entrevista, ao que Sennett (2005) denomina de organização tipo rede, por meio das quais as regras de trabalho pouco fixas, que suscitam do trabalhador tarefas mal delimitadas, fazem com que a instabilidade das relações pareça normal e a rede de relações se redefina numa constância tal que a cultura social mude e passe a considerar objetivos em curto prazo em detrimento dos planejamentos em longo prazo.

O curso de graduação em Psicologia na Universidade Federal do Pará possui duração de 5 (cinco) anos, há um ano os quatro entrevistados estão na graduação e no transcurso deste tempo estão obtendo renda informal com as vendas de produtos, 
e é uníssono o posicionamento dos 4 (quatro) entrevistados de que pretendem manter as vendas para aquisição de renda porque os projetos a curto prazo são de atenção emergencial, mesmo quando questionados sobre projetos de longo prazo, como estágio, emprego na área, a resposta é consensual no caminho de que as incertezas a curto prazo não fornecem uma base pensar melhor sobre previsões futuras.

O jovem universitário com o perfil dos participantes busca sobreviver às diretrizes de uma economia com ideologia neoliberal, que veicula interesses individuais que garantem a liberdade de escolha pela obrigatoriedade do trabalho, lançando os meios coercitivos de adesão eficaz do trabalhador. A liberdade no Brasil é assistida, a livre escolha é pautada nos ditames de valorização do trabalho e refutação ao ócio, que seria altamente prejudicial ao bem-estar do indivíduo (Gonçalves, 2010).

\subsection{Evasão, assistencialismo e políticas públicas}

Quando a evasão do sistema, perda do vínculo com a instituição de ensino, é um problema de ordem pública? A evasão universitária é um processo com vertente economicista, e também utilitarista, que em dimensões macro podem afetar a sociedade em geral. Prestes e Fialho (2018) acreditam que há estreita relação entre a qualificação da população economicamente ativa (PEA) e os modelos de desenvolvimento econômicos e sociais adotados pelo país, e que a evasão pode ser voluntária ou involuntária.

No primeiro semestre de 2019 a Associação Nacional dos Dirigentes das Instituições Federais de Ensino Superior Andifes, apresentou ao público um documento intitulado V Pesquisa Nacional de Perfil Socioeconômico e Cultural dos (as) Graduando (as) das IFES coletado em 2018, no concernente a evasão universitária, este documento destaca que "os aspectos financeiros relacionados à vida pessoal ou familiar do estudante" $(2018$, p. 178) é uma das possibilidades que podem interromper o processo de instrução acadêmica, sendo considerada uma causa de evasão voluntária, na qual o aluno requer desligamento da instituição.

Com base na entrevista com os 4 (quatro) graduandos, há plausibilidade nessa hipótese, pois todos relataram que a remuneração informal que percebem é fundamental para que permaneçam na Universidade, vez que 3 (três) deles apesar de acreditarem precisar, não percebem nenhum auxílio permanência do governo, e 1 (um) deles apesar de estar recebendo bolsa por estágio ligado à Instituição Federal de Ensino Superior - IFES, afirma que não pretende deixar de complementar a renda.

O fenômeno da evasão universitária é preocupante dentro da concepção produtivista da educação porque cada aluno de uma IFES possui um valor de custo para o governo, a partir do momento em que este discente não completa sua instrução especializada, aqueles recursos públicos que foram destinados ao fomento de sua vaga se convertem em déficit aos cofres públicos, acarretando consequências negativas à gestão universitária.

Nesse sentido, em 1995 foi constituída a Comissão Especial de Estudos sobre Evasão pela Secretaria de Educação Superior a fim de fortalecer uma série de políticas públicas, programas e planos educacionais, para minimizar os efeitos negativos deste fenômeno, no Brasil a discussão a este respeito está em torno do que é assistencialismo e o que são políticas públicas.

O assistencialismo, conforme elucida Sposati (2018), no Dicionário de Políticas Públicas, não é uma prática governamental reconhecida como um direito de acesso do assistido às suas necessidades, é como uma caridade e não um dever do Estado. Em muitos aspectos o próprio Estado, na figura de seus representantes, descontinua políticas públicas de governos antecedentes por acreditarem que o investimento de verbas para projetos para desenvolvimento de ciência e tecnologia são assistencialistas, e, portanto, optativos.

Este é um comportamento transgressor pois a educação e o trabalho não devem estar a serviço do Estado e sim este tem como dever precípuo manejar políticas públicas em serviço da população para o desenvolvimento da sociedade a qual 
representa. A educação no Brasil necessita de Políticas Públicas, ações políticas de intervenção planejada e dimensão subjetiva de fenômenos sociais, que busquem dirimir problemas como a evasão universitária.

Por exemplo, o relatório linha de base 2018 exarado pelo Instituto Nacional de Estudos e Pesquisas - INEP, dispôs que quanto ao Plano Nacional de Educação (PNE) 2014-2024, no que concerne a Meta 12, referente a educação superior, o objetivo é "Elevar a taxa bruta de matrícula na educação superior para 50\% (cinquenta por cento) e a taxa líquida para $33 \%$ (trinta e três por cento) [...] assegurada a qualidade da oferta e expansão para, pelo menos, $40 \%$ (quarenta por cento) das novas matrículas, no segmento público".

Contudo a política pública deve se ater a todas as nuances da questão, o governo deve estar concentrado nas resoluções de problemas, no caso em comento, o Estado trabalha um plano de expansão, mas não um projeto de contenção das evasões. Pois na sociedade salarial a dignidade está atrelada a inserção do indivíduo no mundo do trabalho de onde provêm sua construção identitária humana (Chaves, 2020).

\section{Conclusão}

O Estado brasileiro se pauta mais a ideologia do que a execução, falta ao país subsídios advindos de políticas públicas com foco na absorção e na demanda de mão de obra qualificada. Isso explica o sucateamento direcionado ao fomento de projetos de pesquisa científica e tecnológica no país.

A sociedade vive a utopia da liberdade, mas já dizia José Saramago (2013), que a liberalização também está revestida de escravatura. $\mathrm{O}$ capitalismo monopolista possibilitou uma sensação de unanimidade, mas sem a conformidade, isso porque o direito ao bem-estar está vinculado as demandas do processo produtivo, a efetivação da ordem social passa a ser controlada por uma dimensão dupla e contraditória em que o governo almeja muito, investindo pouco.

Essa cultura da concepção produtivista da educação está muita enraizada na sociedade brasileira, e alimenta o mito de que aqueles que possuem nível superior completo estarão à salvo da temerosa precarização do trabalho, quando o que nós observamos é que a precarização atinge a todos, mesmo os estudantes, porque esse fenômeno não está ligado a qualificação profissional e sim ao lugar que o trabalhador ocupa no modo de produção.

Assim, a partir da observação do desamparo ao estudante universitário e seu trabalho informal, conclui-se que as pessoas, em geral, buscam sobreviver e o Estado reflete a emergência social, pois a ausência de um projeto de crescimento do país acaba incitando uma falta de expectativa maior da população com relação a potencialidade de crescimento econômico e financeiro da nação, a falta de credibilidade e confiança no governo se desdobra no adoecimentos de uma sociedade desorganizada e enredada na cultura da execução a curto prazo em detrimento de planejar a longo prazo.

Portanto, para além das pesquisas teóricas que apontem os déficits políticos na educação, a realidade urge, também, por pesquisas empíricas, hipotético-dedutivas, que demonstrem o resultado prático do sucateamento do ensino, como o cotejo entre a quantidade de alunos beneficiados por algum programa de políticas publicas que lhes apoie a permanecer no processo de educação versus o quantitativo de alunos que não recebem esse benefício e a relação desses fenômenos com a evasão universitária, a fim de deslindar para a população o fenômeno cíclico de abstração concreta que reduz todo bem a mercadoria no Brasil.

\section{Referências}

Azevedo. J. E. (Org.). Camacho. A. R. (2017). Introdução às ciências sociais: Évora.

Chaves, A. B. P. (2020). Da Planta tayloristalfordista ao capitalismo de plataforma: as engrenagens da exploração do trabalho. Research, Society and Development. 9(6) e01963473. 
Research, Society and Development, v. 10, n. 5, e3710514548, 2021

(CC BY 4.0) | ISSN 2525-3409 | DOI: http://dx.doi.org/10.33448/rsd-v10i5.14548

Chaves, A. B. P., \& Almeida, L. J. S. (2020). A política do retrocesso: educação e desigualdades no Brasil. Research, Society and Development. 9(8) e548985957.

Durkheim, E. (2007). As regras do método sociológico: Martins Fontes.

Faria, R. (2019). Investimento estrangeiro explode no país, mas não gera emprego. <https://osnovosinconfidentes.com.br/investimento-estrangeiro-explodeno-pais-mas-nao-gera-emprego/>.

Friedman, M. (2017). Capitalismo e liberdade. Tradução Afonso Celso da Cunha Serra. LTC.

Geromel, R. (2019). O poder da China: o que você deveria saber sobre o país que mais cresce em bilionários e unicórnios: Editora Gente.

Giovanni, G., \& Nogueira, M. A. (org.) (2018). Dicionário de políticas públicas (3a ed.): Editora UNESP.

Gonçalves, M. G. M. (2010). Psicologia, subjetividade e políticas públicas. Cortez.

Instituto Nacional de Estudos e Pesquisas - INEP. (2018). Plano Nacional de Educação - PNE. 〈http://simec.mec.gov.br/pde/grafico_pne.php〉.

Lei n..$^{\circ}$ 5.692/71, de 11 de agosto de 1971. Fixa Diretrizes e Bases para o ensino de $1^{\circ}$ e $2^{\circ}$ graus, e dá outras providências. Diário Oficial da União: seção 1 , Brasília, DF, 6377.

Lei n. ${ }^{\circ}$ 9.394/96, de 20 de dezembro de 1996. Estabelece diretrizes e bases da educação nacional. Diário Oficial da União: seção 1, Brasília, DF, ano 134, n. 248 , p. 1.

Malan, P. (2018). Uma certa ideia de Brasil. Intrínseca.

Pinsky, C. B., \& J. (orgs). (2018). História da Cidadania. (6a ed.): Contexto.

Prestes, E. M. T., \& Fialho, M. G. D. (2018). Evasão na educação superior e gestão institucional: o caso da Universidade Federal da Paraíba. <https://doi.org/10.1590/S0104-40362018002601104>.

Santos, M. (2005). Da Totalidade ao Lugar: Editora da Universidade de São Paulo.

Santos, M. (2002). O País distorcido: o Brasil, a globalização e a cidadania: Publifolha.

Saramago, J. (2013). Democracia e universidade: ed.ufpa; Fundação José Saramago.

Saviani, D. (2006). Política e educação no Brasil: o papel do Congresso Nacional na legislação do ensino. (6a ed.): Autores Associados.

Sennett, R. (2005). A corrosão do caráter - conseqüências pessoais do trabalho no novo capitalismo: Record.

Sousa, J. F. (2020). Direito à educação no Brasil: 2020.

Sposati, A. Assistencialismo. In: DI Giovanni, G. \& Nogueira, M. A. (orgs.). (2018). Dicionário de políticas públicas. (3a ed.): Editora UNESP.

V Pesquisa Nacional de Perfil Socioeconômico e Cultural dos (as) Graduandos (as) das IFES - 2018. Brasília, 2019. <http://www.andifes.org.br/wpcontent/uploads/2019/05/V-Pesquisa-Nacional-de-Perfil-Socioecon\%C3\%B4mico-e-Cultural-dos-as-Graduandos-as-das-IFES-2018.pdf>. 